\title{
Atividade citotóxica do extrato de Croton urucurana Baill contra linhagens de células leucêmicas humanas U937 e THP1
}

\author{
Cytotoxic activity of Croton urucurana Baill extract against human leukemic cell lines U937 \\ and THP1
}

Geisla Teles Vieira ${ }^{1}$, Tânia Toledo de Oliveira ${ }^{2}$, Luana Pereira Monteiro ${ }^{3}$, Milton Masahiko Kanashiro ${ }^{4}$, Marcelo Rocha da Costa $^{5}$ e Wander Lopes Pereira ${ }^{6}$

1,2,3,5,6 Universidade Federal de Viçosa

geislateles@yahoo.com.br; ttoledo@ufv.brluanapmonteiro@yahoo.com;.brmarcelorochadacosta@yahoo.com.br;wolope9@gmail.com

${ }^{4}$ Universidade Estadual do Norte Fluminense Darcy Ribeiro

hiko.kanashiro@gmail.com

\section{RESUMO}

As leucemias são neoplasias malignas que acometem as células do sangue e têm origem na medula óssea. São cânceres de grande incidência e de dificil tratamento, havendo, portanto, a uma constante procura por terapias mais eficientes. O presente trabalho investigou a ação citotóxica do extrato hidroalcoólico de Croton urucurana em células leucêmicas humanas U937 e THP-1. As linhagens de células U937, THP-1 foram plaqueadas em volume de $100 \mu \mathrm{L} /$ poço $\left(1 \times 10^{6} \mathrm{cels} / \mathrm{mL}\right)$ em placas de 96 poços, tratadas com extrato nas concentrações finais de $50 \mu \mathrm{g} / \mathrm{mL}, 100 \mu \mathrm{g} / \mathrm{mL}, 200 \mu \mathrm{g} / \mathrm{mL}$ e $400 \mu \mathrm{g} / \mathrm{mL}$ e $800 \mu \mathrm{g} / \mathrm{mL}$ para os testes de viabilidade celular com MTT (-3-(4,5-dimetil-2-tiazol) 2,5-difenil-2-H-brometo de tetrazom). Após 48h, a viabilidade foi avaliada pelo MTT e o sobrenadante utilizado para dosagem da enzima Lactato Desidrogenase (LD). Microscopia de fluorescência foi usada para avaliar a apoptose. O extrato foi capaz de reduzir a viabilidade celular pelo ensaio MTT, aumentar liberação da LD e de induzir apoptose em ambas as linhagens de células testadas nas concentrações 400 e $800 \mu \mathrm{g} /$ $m L(p \leq 0,05)$. O extrato de C. urucurana apresentou atividade citotóxica contra as linhagens de célula leucêmicas humanas U937 e THP-1, apresentando-se como promissor na busca por novos agentes antineoplásicos.

Palavras-chave: Leucemia; Croton urucurana; linhagens de células U937 e THP-1

\section{ABSTRACT}

Leukemias are malignant neoplasms that affect blood cells and originate in bone marrow. These are cancers of high incidence and are difficult to treat and there is a constant search for more efficient therapies. The present work investigated the cytotoxic action of the hydroalcoholic extract of Croton urucurana in human leukemia cells U937 and THP-1. The U937 and THP-1 cell lines were plated in a $100 \mu \mathrm{L} /$ well volume (1x106 cells $/ \mathrm{mL})$ in 96-well plates, treated with extracts at final concentrations of $50 \mu \mathrm{g} / \mathrm{mL}, 100 \mu \mathrm{g} / \mathrm{mL}, 200 \mu \mathrm{g} / \mathrm{mL}$ and $400 \mu \mathrm{g} / \mathrm{mL}$ and 800 $\mu \mathrm{g} / \mathrm{mL}$ for cell viability tests with MTT(-3- (4.5-dimethyl-2-thiazole) 2.5-diphenyl-2H-tetrazolium bromide). After $48 h$, viability was assessed by MTT and the supernatant was used for determination of the Lactate Dehydrogenase (LD) enzyme. Fluorescence microscopy was used to evaluate apoptosis. The extract was able to reduce cell viability by the MTT assay, increase $L D$ release and induce apoptosis in both cell lines tested at concentrations of 400 and $800 \mu \mathrm{g} / \mathrm{mL}(p \leq 0.05)$. The C. urucurana extract presented cytotoxic activity against human leukemic cell lines U937 and THP-1, presenting itself as promising in the search for new antineoplastic agents.

Keywords: Leukemia; Croton urucurana; U937 and THP-1 cell lines 


\section{Introdução}

Produtos naturais são fonte significativa de medicamentos ao longo da história. Estudos epidemiológicos demonstram que a incidência de câncer está inversamente proporcional ao consumo de dietas ricas em produtos de origem vegetal (CHAHAR et al., 2011). Esses produtos apresentam papel dominante no desenvolvimento de quimioterapêuticos, sendo que $74 \%$ dos compostos anti-cancerígenos advém de produtos naturais ou derivados destes (AIT-MOHAMED et al., 2011; ZHANG et al., 2011). Para tanto, pode-se citar como exemplos, os alcaloides: vincristina e vimblastina obtidos a partir da espécie vegetal Catharantus roseus e utilizadas para tratamento de linfomas e leucemia infantil, e também o diterpeno taxol extraído da árvore Taxus brevifolia, utilizado para o tratamento do câncer ovariano, mamário e pulmonar (GURIB-FAKIM, 2006).

$\mathrm{Na}$ cultura popular brasileira extratos de plantas são utilizados para tratamento de várias doenças, inclusive para o câncer. A espécie Croton urucurana Baill, conhecida popularmente como sangra d'água, sangue de dragão é uma árvore da família Euphorbiaceae, distribuída nas Américas e Ásia. Na medicina popular brasileira, preparados farmacológicos da casca das espécies de Croton vêm sendo utilizado como analgésico, antiinflamatório e anticancerígeno (RANDAU et al., 2002). Da casca da árvore, extrai-se um látex vermelho que é utilizado como cicatrizante, antibiótico, purgativo e curativo para micoses (PASA et. al, 2005).

Extratos de Croton urucurana foram descritivos por apresentarem atividades antibacterianas contra Staphylococcus aureus e Salmonella typhimurium (PERES et al., 1997), antifúgica contra fungos causadores de micoses de peles (GURGEL 2005), antimicrobiana e antioxidante (SIMIONATTO, 2007); anti-hemorrágica (ESMERALDINO, 2005) e analgésica (PERES et al., 1998b). OLIVEIRA et al 2008 relatam ações antibacteriana em uma triagem in vitro do látex e extratos de Croton urucurana. As ações farmacológicas de C. urucucana, devem- se a presença de compostos bioativos presentes em seus extratos e em suas frações, como por exemplo, o ácido acetilaleuritólico, esteróis (sitosterol, estigmasterol e campesterol), diterpenos (sonderianina), campesterol, $\beta$-sitosterol, stigmasterol, ácido acetil aleurítico, catequina, gallocatequina e glicosídeo de sitosterol (PERES et al., 1997), alcaloides, flavonoides e terpenoides (RANDAU et al., 2004).

Os efeitos adversos associados ao uso de fitoterápicos e plantas medicinais ocorrem comumente, mas no Brasil a notificação dos eventos toxicológicos não é obrigatória, o que favorece a subnotificação (CAMPOS et al., 2016). A hipersensibilidade é um dos efeitos colaterais mais comum causado pelo uso de plantas medicinais (PERHARIC et al., 1993). Como exemplos de efeitos tóxicos de substâncias presentes em plantas podem ser citados os efeitos hepatotóxicos de apiol, safrol lignanas e alcaloides pirrolizidínicos; a ação tóxica renal que pode ser causada por espécies vegetais que contém terpenos e saponinas e alguns tipos de dermatites, causadas por espécies ricas em lactonas sesquiterpênicas e produtos naturais do tipo furanocumarinas (CAPASSO ET AL., 2000). Hepatite tóxica foi registrada em pacientes que fizeram uso indevido (folhas com indicação de cascas em tratamentos prolongados) de Croton cajucara e, eczemas foram relatadas após exposições repetidas ao látex extraído das cascas de Croton (VEIGA JUNIOR et al., 2005).

As leucemias são neoplasias malignas que acometem as células do sangue e tem origem na medula óssea (KAATSCH et al., 2010; PARK et. al., 2013). Conforme o tipo celular envolvido e o estágio de maturação, as leucemias podem ser classificadas em leucemias mielocíticas (mieloblásticas) agudas e crônicas e leucemias linfocíticas (linfoblásticas) agudas e crônicas (KUMAR et al., 2005; GOULAS et al., 2009). Leucemia linfocítica crônica afeta adultos acima dos 55 anos. Já a leucemia linfocítica aguda é mais comum na infância causando morte se não for controlado (EBY, 2005; KONAN et al., 2012). A leucemia mielóide aguda (LMA) é caracterizada pelo crescimento rápido de células brancas do sangue anormais e interferem na produção de células sanguíneas normais. (DOHNER et al., 2010). Este tipo de câncer é de grande incidência e de difícil tratamento, havendo, portanto, uma constante procura por terapias mais eficientes. O principal tratamento para a leucemia é a quimioterapia. Os pacientes tratados com quimioterapia atingem remissões completas, mas transitória e, em seguida, desenvolvem resistência ao tratamento quando ocorre recidiva da doença.

Frente à alta incidência de casos de câncer no mundo e seu alto grau de morbidade e letalidade, aliado a procura de tratamentos mais efetivos e seletivos no combate ao câncer, torna-se de extrema importância pesquisas de novos compostos que apresentem características anti-carcinogênicas. A pesquisa pretende alcançar os seguintes objetivos: verificar o efeito citotóxico do extrato de Croton urucurana contra as linhagens de células leucêmicas U937 e THP-1; bem como verificar se o extrato induz morte celular por apoptose.

\section{Material e métodos}

\section{Material vegetal}

O material botânico (galhos, flores, folhas e entrecasca) foi coletado em uma área de reserva natural de Mata Atlântica, do tipo Floresta Estacional Semi Decidual, localizado no município de João Monlevade, em Minas Gerais (19 48' 36” e 43 10 '26” W). A planta foi identificada pelo botânico taxonomista Marcus Simão do Departamento de Biologia da Universidade Federal de Viçosa (UFV), e, uma exsicata foi depositada no Herbário VIC da UFV (exsicata n ${ }^{\mathrm{o}} 38.756$ ). 


\section{Preparo do extrato hidroalcoólico}

As cascas e entrecascas foram limpas mecanicamente, lavadas com água destilada, desinfetadas com hipoclorito de sódio $2 \%$, secas em estufa a $40^{\circ} \mathrm{C}$ até peso constante, trituradas e moídas. As cascas e entrecascas moídas $(100 \mathrm{~g})$ foram maceradas em solução água: álcool etílico P.A $50 \%$ por $72 \mathrm{~h}, 25^{\circ} \mathrm{C}$, ao abrigo da luz. O macerado foi filtrado e o extrato concentrado em evaporador rotativo à baixa pressão entre 45 a $55^{\circ} \mathrm{C}$, e liofilizado. Este procedimento foi repetido até completa exaustão do material vegetal. Ao final, o extrato foi pesado e o rendimento foi de $8,2 \%(\mathrm{p} / \mathrm{p})$ em relação ao material em pó seco.

\section{Linhagens e cultivo celular}

As linhagens de células U937, (leucemia de origem linfoide) e THP-1 (leucemia monocítica aguda) foram adquiridas da American Type Culture Collection (ATCC, Manassas, VA, EUA) e obtidas do Laboratório de Biologia do Reconhecer do Centro de Biociências e Biotecnologia da Universidade Estadual Norte Fluminense, Campos dos Goytacazes, RJ. As células foram cultivadas em meio D-MEM F12 suplementado com $20 \mu \mathrm{g} / \mathrm{mL}$ de gentamicina e $10 \%$ de soro fetal bovino (Gibco, BRL). As culturas foram replicadas a cada 2 dias e mantidas em estufa a $37^{\circ} \mathrm{C}$, com $5 \%$ de $\mathrm{CO} 2$ e umidade controlada.

\section{Ensaios MTT e LD}

As linhagens de células U937, THP-1 foram plaqueadas em volume de $100 \mu \mathrm{L} /$ poço (1x106cels $/ \mathrm{mL})$ em placas de 96 poços, tratadas com o extrato bruto de Croton urucuana nas concentrações finais de $50 \mu \mathrm{g}, 100 \mu \mathrm{g}, 200 \mu \mathrm{g}$ e $400 \mu \mathrm{g}$ e $800 \mu \mathrm{g} / \mathrm{mL}$ para os testes de viabilidade celular com MTT (-3-(4,5-dimetil-2-tiazol) 2,5-difenil-2-H-brometo de tetrazom). As células foram mantidas em estufa a $37^{\circ} \mathrm{C}$, com $5 \%$ de $\mathrm{CO} 2$ e umidade controlada. No tempo de 48 horas a viabilidade celular foi avaliada pelo MTT. Parte do sobrenadante das culturas foi utilizada para a dosagem da enzima Lactato Desidrogenase (LDH). A determinação da LD é proporcional ao número de células mortas por necrose in vitro. A enzima LDH liberada pelas células U937 e THP-1 foi mensurada em espectrofotômetro após 48 horas de tratamento com o extrato de Croton urucurana em diferentes concentrações de 50, 100, 200, 400, $800 \mu \mathrm{g} / \mathrm{mL}$, utilizando KIT DOLES de mensuração.

\section{Avaliação de apoptose por Microscopia de fluorescência}

As células U937 e THP-1 foram incubadas por 12, 24, 36 horas com o extrato bruto de C. urucuana nas concentrações de $50,100,200,400,800 \mu \mathrm{g} / \mathrm{mL}$. Em seguida, foram coradas com uma solução de $10 \mu \mathrm{g} / \mathrm{mL}$ laranja de acridina e $10 \mu \mathrm{g} / \mathrm{mL}$ de brometo de etídio. Após as montagens em lâminas e lamínulas, as células foram avaliadas quanto à taxa de apoptose e necrose por microscopia de fluorescência (Axioplan - Zeiss), sendo contadas em aproximadamente 300 células em vários campos escolhidos aleatoriamente, descriminando-se as células apoptóticas, necróticas e normais.

\section{Análise estatística}

Os resultados foram expressos por média \pm desvio padrão, analisados de forma independente. Os ensaios foram analisados por ANOVA - One-way - seguido de Tukey utilizando o programa Graph Pad versão 5.0. As diferenças significativas foram consideradas como $\mathrm{p}<0,05$.

\section{Resultados e discussão}

\section{Determinação da viabilidade da célula U937 e THP-1 tratada com o extrato de Croton urucurana}

\section{- ensaio MTT}

Nota-se na Figura 1, que o extrato hidroalcoólico de C. urucurana reduziu a viabilidade celular das linhagens U937 e THP-1 nas concentrações 400 e $800 \mu \mathrm{g} / \mathrm{mL}$.

Para efeito de uma melhor comparação da atividade dos compostos contra as duas linhagens de células testadas, foi calculada a dose efetiva (EC50) com base no teste de MTT. Extrato de Croton urucurana apresentou valores de EC50 de 402,2 $\mu \mathrm{g} / \mathrm{mL}$ e $360,3 \mu \mathrm{g} / \mathrm{mL}$ para as linhagens de células testadas U937 e THP-1, respectivamente. Estes valores representam a concentração do composto capaz de matar 50\% das células testadas. Os valores de EC50 indicam que a linhagem THP-1 é mais sensível ao extrato do que U937. Como controle positivo foi avaliado o efeito citotóxico do fármaco vincristina, composto orgânico usado na terapia destas linhagens de células carcinogênicas. Vincristina apresentou EC50 de 6.46 $\pm 1,13 \mu \mathrm{M}$ e 26,15 $\pm 1,24$ 


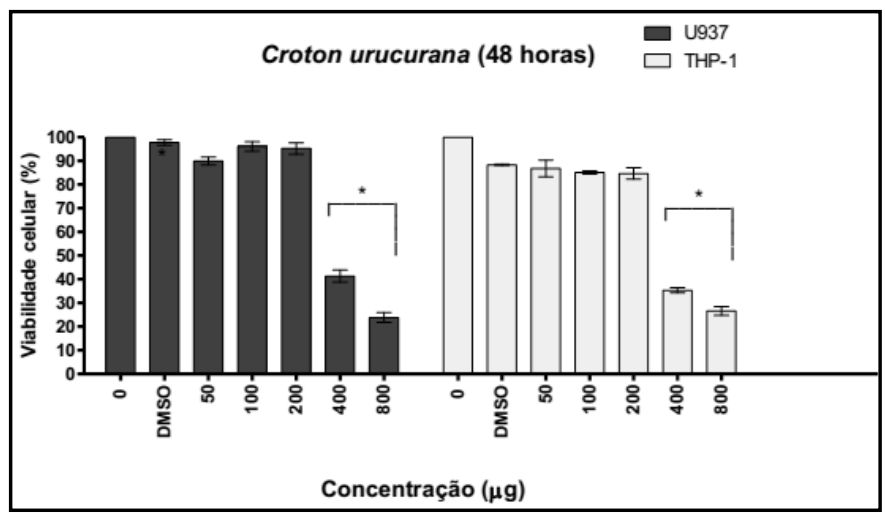

Figura 1 - Efeito citotóxico do extrato de Croton urucurana contra as células leucêmicas humanas U937 e THP-1 após 48 horas de incubação através do ensaio colorimétrico utilizando MTT. Zero significa o controle negativo do teste (células e meio de cultivo). A concentração de DMSO foi de $1 \%$. ${ }^{*} \mathrm{p}<0.05$; valor estatisticamente significante em relação ao controle negativo (zero) pelo teste Tukey

$\mu \mathrm{M}$ para as linhas U937 e THP-1, respectivamente. Os ensaios MTT e EC50 mostram que o extrato de C. urucurana apresentou capacidade citotóxica, pois inibiu o desenvolvimento de células tumorais das linhagens testadas.

O fármaco vincristina é um alcaloide dimérico encontrado na Vinca (Catharantus roseus L.), pertencente à classe de antitumorais mais utilizados atualmente. Sua atividade citotóxica está baseada na habilidade de inibir a dinâmica e arranjo de microtúbulos, ligando-se à tubulina, inibindo a sua proliferação em microtúbulos, impedindo a formação do fuso mitótico paralisando assim a divisão celular e, portanto, inibindo o crescimento da célula tumoral durante a metáfase (estágio importante de divisão nuclear da célula) (BRANDAO, 2010). Os resultados de EC50 mostram que a concentração do fármaco vincristina utilizada para alcançar $50 \%$ da morte celular foi consideravelmente menor quando comparado às concentrações atingidas pelo extrato de C. urucurana. Este resultado já era esperado uma vez que a vincristina trata-se de um composto já isolado e que no extrato de C. urucurana não há o isolamento de substâncias bioativas. Estas são encontradas no extrato e atuam de forma sinérgica.

\section{Avaliação da viabilidade celular pela liberação da lactato desidrogenase (LDH)}

$\mathrm{Na}$ Figura 2 pode-se observar que as linhagens tratadas com o extrato apresentaram aumento de liberação da enzima LDH nas concentrações 400 e $800 \mu \mathrm{g} / \mathrm{mL}$. Isto permite dizer que o extrato de C. urucurana promoveu a ruptura da membrana plasmática nas maiores concentrações o que confirma a redução da viabilidade celular pelo método de MTT.

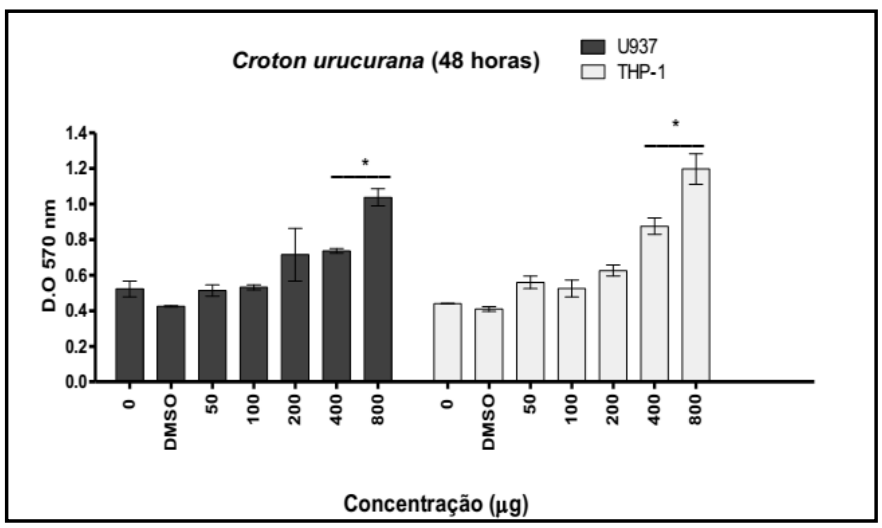

Figura 2 - Avaliação da liberação da LDH (desidrogenase láctica) em células U937, THP-1, tratadas com diferentes concentrações do extrato C. urucurana durante $48 \mathrm{~h}$. O zero significa o controle negativo do teste (células e meio de cultivo). A concentração de DMSO foi de $1 \%$. ${ }^{*} \mathrm{p}<0.05$, valores estatisticamente significantes em relação ao controle negativo (zero)

A LDH é uma enzima citosólica que é normalmente encontrada no interior das células saudáveis. A LDH permite analisar o número de total de células viáveis, isto correlacionado com a proliferação das mesmas. Entretanto, quando há indução de danos celulares por agentes químicos, pode ocorrer aumento da permeabilidade da membrana celular, liberando a LDH no meio (GLINOS et al., 1965). Os resultados obtidos com esta técnica corroboram aos resultados obtidos pelo ensaio com MTT, deste modo, o aumento da dosagem da enzima LDH de maneira concentração dependente confirmou o efeito citotóxico do extrato de $\mathrm{C}$. urucuarana frente às linhagens neoplásicas. 


\section{Avaliação do mecanismo de morte celular}

O extrato foi capaz de induzir apoptose nas linhagens de célula THP-1 nas concentrações 400 e $800 \mu \mathrm{M}$ para o período de tempo de 36 e 48 horas chegando a $75 \%$ na concentração de $800 \mu \mathrm{g} / \mathrm{mL}$ em 48 horas (Figura 3). Para a linhagem U937 o extrato foi capaz de induzir a apoptose nas concentrações 200,400 e $800 \mu \mathrm{g} / \mathrm{mL}$ para o período de tempo de 24,36 e 48 horas chegando a $100 \%$ na concentração $800 \mu \mathrm{g} / \mathrm{mL}$ para 48 horas (Figura 4). Observa-se que a linhagem U937 é mais sensível ao extrato, nas mesmas concentrações e períodos de tempo.



Figura 3 - Porcentagem de apoptose induzida pelo extrato de Croton urucurana nas linhagens neoplásicas THP-1 determinada por microscopia de fluorescência em quatro tempos diferentes, 12, 24, 36 e 48h. O zero significa controle negativo do teste (células e meio de cultivo). A concentração de DMSO foi de $0,2 \%$. ${ }^{*} \mathrm{p}<0.05$, valores estatisticamente significantes em relação ao controle negativo (zero)



Figura 4 - Porcentagem de apoptose induzida pelo extrato de Croton urucurana nas linhagens neoplásicas U937, determinada por microscopia de fluorescência em quatro tempos diferentes, 12, 24, 36 e 48h. O zero significa controle negativo do teste (células e meio de cultivo). A concentração de DMSO foi de $0,2 \%$. ${ }^{*} \mathrm{p}<0.05$, valores estatisticamente significantes em relação ao controle negativo (zero)

Apoptose é um processo de morte celular altamente regulado, fundamental para o controle da fisiologia celular e dos tecidos, em resposta a estímulos internos e externos, os quais levam à morte celular em poucas horas. Grande parte dos fármacos antitumorais promove a morte das células cancerígenas através do mecanismo de apoptose (PARK, 2013). Compostos que promovem apoptose como via de indução de morte celular são fortes candidatos a fármacos com ação antitumoral (KONAN et al., 2012; ONRUBIA et al., 2012). Extrato da casca/entrecasca de C. urucurana foi capaz de induzir a morte das células leucêmicas U937 e THP-1.

As cascas de C. urucurana, descrevem a presença de ácido acetilaleuritólico; dos flavonóides catequina e galocatequina; dos diterpenos clerodanos sonderianino, 12-epi-metilbarsbacoato e 15,16-epoxy-3,13(16)-clerodatrieno-2-ona; e dos esteróis: campesterol, stigmasterol, sitosterol e seu glicosídeo (PERES et al., 1997; PERES et al., 1998a; PERES et al., 1998b). A atividade antitumoral de vários flavonóides está atribuída a sua eficiência em inibir as enzimas topoisomerases I e II (SUKARDIMAN et al., 2000), diminuir a proliferação celular como consequência de sua ligação ao receptor de estrógeno (PRIMIANO et al., 2001), apresentar atividade inibidora de proteínas quinases (GAMETPAYRASTRE et al., 1999), e/ou induzir apoptose e liberação do citocromo c (LU et al., 2010).

Estudos comprovam que os flavonoides de espécies de Croton induziram o bloqueio no ciclo celular na fase G2/M e promoveu apoptose pela via intrínseca em células leucêmicas (KUO, 2007). Sugere-se que a presença de flavonoides no extrato da casca/entrecasca de C. urucurana seja a causa da indução da apoptose.

Com ampla utilização na medicina tradicional (GUPTA et al., 2008; BARRERA et al., 2016), diferentes espécies de Croton 
exibem potencial anti-tumoral in vivo e in vitro (NATH et al., 2013). Nossa perspectiva foi conduzir estudos avaliando a citotoxicidade do extrato hidroalcoólico de C. urucurana sobre células tumorais investigando o sinergismo bioquímico e seu IC50 em associações com diferentes quimioterápicos; o isolamento do principal composto bioativo desta espécie e seu mecanismo de ação antitumoral podem fornecer resultados promissores no tratamento da leucemia.

\section{Conclusões}

O presente estudo demonstrou que o extrato hidroalcoólico da casca/entrecasca de Croton urucurana apresentou atividade citotóxica contra as linhagens de célula leucêmicas humanas U937 e THP-1, apresentando-se como promissor na busca por novos agentes antineoplásicos. Esta pesquisa foi realizada in vitro e novas pesquisas necessitarão ser conduzidas em fase pré-clínica e clínica nas áreas farmacológica e toxicológica para se estabelecer doses farmacológicas terapêuticas seguras. Entretanto, mais pesquisas devem ser realizadas a fim de elucidar as vias de indução de apoptose promovida por este extrato nas linhagens neoplásicas avaliadas, bem como a elucidação das substâncias bioativas e seu modo de ação.

\section{Agradecimentos}

Agradecimentos aos revisores, colaboradores e as agências de fomento CAPES, FAPEMIG e a rede TOXIFAR.

\section{Referências}

Ait-Mohamed, O., Battisti, V., Joliot, V., Fritsch, L., Pontis, J., Medjkane, S., Redeuilh, C., Lamouri, A., Fahy, C., Rholam, M. (2011). Acetonic extract of buxus sempervirens induces cell cycle arrest, apoptosis and autophagy in breast cancer cells. PLoS One, 6 (9), e24537.

Barrera, C., Andrés, C., Constanza Gómez, D., Castiblanco, F. A. (2016). Importancia medicinal del género Croton (euphorbiaceae). Revista Cubana de Plantas Medicinales, 21(2), 234-247.

Brandão, H. N., David J. P., Couto R. D., Nascimento. A. P., David J. (2010). Química e farmacologia de quimioterápicos antineoplásicos derivados de plantas. Química Nova, 33(6), 1359-1369.

Chahar, M. K., Sharma, N., Dobhal, M. P., Joshi, Y.C. (2011). Flavonoids A versatile source of anticancer drugs. Pharmacologic Review, 5(9), 1-12.

Capasso, R., Izzo A.A., Pinto L., Bifulco, T., Vitobello, C., Mascolo, N. (2000). Phytotherapy and quality of herbal medicines. Fitoterapia, 71(1), S58-S65.

Campos, S.C., Silva, C.G., Campana, P.R.V., Almeida, V.L. (2016). Toxicidade de espécies vegetais. Rev. Bras. Pl. Med., Campinas, 18(1), 373-382.

Dohner, H., Estey, E. H., Amadori, S., Appelbaum, F. R., Buchner, T., Burnett, A. K., Dombret, H., Fenaux, P., Grimwade, D., Larson, R. A., Lo-Coco, F., Niederwieser, D., Ossenkoppele, G. J., Sanz, M. A., Sierra J., Tallman, M. S., Löwenberg, B., Bloomfield, C. D. (2010). Diagnosis and management of acute myeloid leukemia in adults: Recommendations from an international expert panel, on behalf of the european leukemianet. Blood, v. 115(3), 453-474.

Eby, A. G. (2005). Treatment of acute lymphocytic leukemia using zinc adjanvant with chemotherapy and radiation - a case history and hypothesis. Medical Hipotheses, 64(6), 1124-26.

Esmeraldino, L.E., Souza, A.M., Sampaio, S.V. (2005). Evaluation of the effect of aqueous extract of Croton urucurana Baillon (Euphorbiaceae) on the hemorrhagic activity induced by the venom of Bothrops jacaraca, using techniques to quantify hemorrhagic activity. Phytomedicine, 12 (8), 570-576.

Gamet-Payrastre, L., Manenti, S., Gratacap, M. P., Tulliez, J., Chap, H., Payrastre, B. (1999). Flavonoids and the inhibition of PKC and PI 3-kinase. General Pharmacology, 32(3), 279-286. 
Glinos, A. D., Werrlein, R.J., Papadopoulos, N. M. (1965). Constitution, viability, and lactate dehydrogenase in stationary-phase L-cell suspension cultures. Science, 150(3694), 350-353.

Goulas, V., Exarchou, V., Troganis, A. N., Psomiadou, E., Fotsis, T., Briasoulis, E., Gerothanassis, I. P. (2009). Phytochemicals in olive-leafs extracts and their antiproliferative activity against cancer and endothelial cell. Molecular Nutrition Food Research, 53(5), 600-608.

Gupta, D., Blekley, B., Gupta, R.K. (2008). Dragons blood: botany, chemistry and therapeutic uses. Journal of ethnopharmacology, 115 (3), 361-80.

Gurgel, L.A., Sidrim, J.J.C., Martins, D., Cechinel Filho., Rao,V. (2005). In vitro antifungal activity of dragon's blood from Croton urucurana against dermatophytes. Journal of Ethnopharmacology, 97 (2), $409-412$.

Gurib-Fakin, A. (2006). Review Medicinal plants: traditions of yesterday and drugs of tomorrow. Molecular Aspects of Medicine, 27, 1-93.

Kaatsch P. (2010). Epidemiology of childhood cancer. Cancer Treatment Review, 36(4), $277-285$.

Kumar, V., Cotran, R. S., Robbins, S. L. (2005). Patologia Básica, 7ª ed. Editora Guanabara Koogan.

Konan, N. A., Lincopan, N., Diaz, I. E. C., Jacysyn, J. F., Tiba, M. M. T., Mendes, J. G. P. A., Bacchi, E. M., Spira, B. (2012). Cytotoxicity of cashew flavonoids towards malignant cells lines, Experimental and Toxicologic Phatology, 64(5), 435-440.

Kuo, H.; Chang, L.; Lin, Y.; Lu, H.,; Yang, J.; Lee, J.; Chung, J. (2007). Morin inhibits the growth of human leukemia HL-60 cells via cell cycle arrest and induction of apoptosis through mitochondria dependent pathway, Anticancer Research, 27(1A), 395-405.

Lu, H. P., Chie, Y. J., Yang, M. S., Lee, C. S., Fu, J. J., Yang, J. S., Tan, T. W., WU, S. H., Ma, Y. S., IP, S. W., Chung, J. G. (2010). Apigenin induces caspase-dependent apoptosis in human lung cancer A549 cells through Bax- and Bcl-2-triggered mitochondrial pathway. International Journal of Oncology, 36(6), 1477-1484.

Nath, R., Roy, S., De, B., Choudhury, M.D. (2013). Anticancer and antioxidant activity of Croton: A review. Int J Pharm Pharm Sci, 5(2), 63-70.

Oliveira, I.S., Lima, J.C.S., Silva, R.M., Martins, D.T.O. (2008). Triagem da atividade antibacteriana in vitro do látex e extratos de Croton urucurana Baillon. Revista Brasileira de Farmacognosia, 18 (4),587-93.

Onrubia, M., Cusidó, R. M., Ramire,z K., Hernández-Vázquez, L., Moyano, E., Bonfill, M., Palazon, J. (2012). Bioprocessing of Plant in Vitro Systems for the Mass Production of Pharmaceutically Important Metabolites: Paclitaxel and its Derivatives, Current Medical Chemistry, 12(7), 887-890.

Park, H. Y., Kim, G., Know, T. K., Hwang, H. J., Kim, N. D., Yoo, Y. H., Choi, Y. H. (2013). Apoptosis induction modulation of the Bcl-2 family of proteins and MAPKs signaling pathway, Mutation Research, 751(2), $101-108$.

Pasa, M. C., Soares, J. J., Guarim-Neto, G. (2005). Estudo etnobotânico na comunidade de Conceição-Açu (alto da bacia do rio Aricá Açu, MT, Brasil). Acta Botanica Brasilica, 19(2), 195- 207.

Perharic L., Shaw D., Murray V. (1993). Toxic effects of herbal medicines and food supplements. Lancet, 17(342), 180-181

Peres, M. T. L. P., Delle-Monache, F., Cruz, A. B., Pizzalatti, M. G., Yunes, R. A. (1997). Chemical composition and antimicrobial activity of Croton urucurana Baillon (Euphorbiaceae). Journal of Ethnopharmacology, 56(3), 223-226.

Peres, M.T.L.P., Pizzolati, M.G., Yunes, R.A., Monache, F.D. (1998a). Clerodane diterpenes of Croton urucurana. Phytochemistry, 49, 171-174. 
Peres, M.T.L.P., Monache, F.D., Pizzolatt,i M.G., Santos, A.R.S., Beirith, A., Calixto, J.B., Yunes, R.A. (1998b). Analgesic compounds of Croton urucurana Baillon. Phamaco chemical criteria used in their isolation. Phytother Res, 12, 209-211.

Primiano, T., Yu, R., Kong, A. N. T. (2001). Signal transduction events elicited by natural products that function as câncer chemopreventive agentes. Pharmaceutical Biology, 39(2), 83-107.

Randau, K. P., Xavier, H. S., Dimech, G. S. Wanderley, A. G. (2002). Avaliação preliminar da atividade farmacológica (antiespasmódica e antiulcerogênica) do extrato aquoso bruto de Croton rhamnifolius H.B.K. e Croton rhamnifolioides Pax \& Hoffm. (Euphorbiaceae). Revista Lecta, 20(1), 61-68.

Randau, K. P., Florêncio, D. C., Ferreira, C. P., Xavier, H. S.(2004). Estudo farmacognóstico de Croton rhamnifolius H.B.K. e Croton rhamnifolioides Pax \& Hoffm. Revista Brasileira de Farmacognosia, 14(2), 89-96.

Simionatto, E., BonanI, V.F.L., Morel, A.F., Roppi, N.R., Raposo Junior, J.L., Stuker, C.Z. (2007). Chemical composition and evaluation of antibacterial and antioxidant activities of the essential oil of Croton urucurana Baillon (Euphorbiaceae) stem bark. Journal of the Brazil Chemical Society, 18 (5), 879-885.

Sukardiman, D. A., Tanjung, M., Darmadi, M. O. (2000). Cytotoxic mechanism of flavonoid from Temu Kunci (Kaempferia pandurata) in cell culture of human mammary carcinoma. Clinical Hemorheology and Microcirculation, 23(2-4), 185-190.

Veiga Junior, V.F., Pinto, A.C., Maciel, M.A.M. (2005). Plantas Medicinais: Cura Segura? Quim. Nova, 28(3), 519528.

Zhang, Z., Teruya, K., Eto, H., Shirahata, S. (2011). Fucoidan extract induces apoptosis in mcf-7 cells via mechanism involving the ros-dependent jnk activation and mitochondria mediated pathways. PLoS One, 6(11), e27441. 